\title{
The Marginal Cost of Saving a Life in Health Care: Age, Gender and Regional Differences in Switzerland
}

\author{
Stefan Felder* and Andreas Werblow**
}

JEL-Classification: H11, I12, I18, J16

Keywords: Marginal cost of saving a life, value of a statistical life, gender, health production, regional diversity

\section{Introduction}

In Switzerland, as in other OECD countries, the longevity of the population continues to rise. Since 1960, Swiss life expectancy has increased by 9 years, from 72 to 81. Parallel to this gain, the income share of health care has increased: while the average annual growth rate of real income has been 2 percent, real health care expenditure has grown by 4 percent per year $(O E C D, 2008)$. As a consequence, the income share of health care expenditure increased from 4.9 percent in 1960 to 11.3 percent in 2006 .

Recent research claims a causality running from wealth to health care expenditure to longevity: rising wealth increases the value of life, which in turn increases the demand for health care, which ultimately decreases mortality and increases longevity. ${ }^{1}$ The trace from increased health care expenditure to lower mortality rates can be explained by the change in technology for treating cardiovascular diseases. The introduction of angioplasty in the early 1980s, stents in the mid 1990 s and new drugs in recent years has led to a substantial reduction of old age mortality and contributed almost half of the total gain in life-years between

* Duisburg-Essen University, Faculty of Economics, 45117 Essen, Germany.

** Dresden University of Technology, Faculty of Business and Economics, 01062 Dresden, Germany.

Acknowledgement: This paper was presented at the 2006 Annual Meeting of the Health Economics Section of the German Economics Association (Verein für Socialpolitik) in Essen and at Research Seminars of the University of Rostock and the University of Bayreuth. We thank the participants for helpful comments as well as two referees which provided most helpful comments and suggestions.

1 See, among others, Hall and Jones (2007) and Becker et al. (2005). 
1980 and 2000 (see Cutler and McClellan, 2001, and Murphy and Topel, 2006, for the USA; Felder, 2006a, for Germany; and Cutler et al., 2006, for the world).

Progress in longevity has been greater for men, who benefited more from the medical innovations in treating heart failures, than for women. A longer life implies larger gains in the value of life for men. For the post 1970 period, Murphy and Topel (2006) calculate net gains in the value of life for men that are twice as high as those for women. While Murphy and Topel's focus is the value of life and its age and gender differences, Hall and Jones (2007) additionally calculate the marginal cost of saving a life. Using US data for the period 1950 to 2000, they estimate a production function for health, regressing the inverse of age-specific 'endogenous' mortality rates to age-specific health care expenditure. The demand side of the model is calibrated to consumption data and estimates of household preference parameters from the literature. Remarkably, HaLL and Jones find similar age profiles for the value and the marginal cost of saving a life. In old age, the willingness to pay for a reduction in mortality decreases as the remaining life horizon shortens, and the marginal cost decreases as the elasticity of the health production function decreases. This lends support to a view that individuals rationally choose their health care expenditure over the life cycle.

In this paper, we follow Hall and Jones and estimate a health production function linking reduced mortality to the use of health care resources. At the same time, we extend the analysis to differentiate by gender and regions. Switzerland is an ideal country for such an analysis as per capita health care expenditures and the population's life expectancy differ significantly among the 26 cantons. Moreover, as in other countries, women in Switzerland live longer and spend more on health care than men. Thus, there is sufficient variance in mortality and health care spending, which allows us to estimate a region-, gender- and age-specific health production function and to derive the corresponding marginal costs of saving a life. The time period considered is the years between 1997 and 2006.

The paper is structured as follows: Section 2 gives information on the data used in this study. Section 3 presents the concept of the marginal cost of saving a life, based on a medical production function. Section 4 presents the empirical model and the results in two parts. The first part studies the Swiss population as a whole, concentrating on differences in the marginal cost of saving a life with respect to age and gender. The focus of the second part is on regional differences of the marginal cost of saving a life, while maintaining the gender issue. Additionally, we test the relationship between the marginal cost of life and the population's average income level in the regions. Section 5 concludes. 


\section{Data}

This study is based on age profiles of health care expenditure and mortality rates in the 26 Swiss cantons for the ten years from 1997 to 2006 . Health care data stem from the social health insurance system and from the federal office of statistics, which publishes annual data on age-specific mortality rates in the cantons. While social health insurance coverage is fixed at the federal level (i.e. a uniform catalogue of health care services), the actual demand for and supply of health care services differs substantially across regions. Correspondingly, premiums are regionally differentiated. ${ }^{2}$ The social health insurance expenditure data distinguishes 20 age groups of health care spending for men and women, starting at $0-5,6-10$ and ending at 96+. Using the producer price index (GDP deflator), we express all health expenditures in 2006 SFr. A recent study calculated price differences of medical services across Swiss cantons for the year 2004 (SCHLEINIGER et al., 2006). We used the 2004 cantonal price indices to adjust cantonal health care expenditure between 1997 and 2004. ${ }^{3}$ Mandatory health insurance only covers about half of total health care expenditure. However, with respect to lifetime enhancing treatments, mandatory expenditures seem prevalent.

Cantonal mortality rates are also available in 20 five-year age groups for the years 1997 to 2006. The population size of some cantons is small, which can result in zero death numbers for some age groups. For this reason, we extended the age intervals to ten years and aggregated the 26 cantons to 20 regions. With the 10 ten-year age groups, 10 years and 20 regions, the number of observations is 2,000 .

In 2006, per capita health care expenditure in social health insurance was 2780 SFr. Per capita health care expenditure of a woman was higher than that of a man by a factor of 1.36 (3195 SFr as against $2351 \mathrm{SFr}$ ). The age profiles for women and men are relatively flat at young ages, with a small gradient beyond age 20. 60-year-olds spend on average $3400 \mathrm{SFr}$ on health care. This amount doubles by the age of 70 and reaches 16,800 SFr for men of age 96+ and 20,600 SFr for women of the same age. The gender difference in health care expenditure is most accentuated between ages 20 and 55 as well as in old age.

2 Except for the regional factor, a so called community rating applies, i.e. premiums must not differ with respect to age, sex or any other risk factor.

3 Cantonal price indices are not available for earlier years, so we could not take into account possible changes in relative regional prices in the years between 1997 and 2003. 
Table 1: Population, Life Expectancy, Per Capita Health Care Expenditures (HCE) in Compulsory Health Insurance and Income in the Six Swiss regions, 1997 and 2006

\begin{tabular}{lc|cc|cc|cc}
\hline & $\begin{array}{l}\text { Population } \\
\left(10^{6}\right)\end{array}$ & \multicolumn{2}{|c|}{$\begin{array}{c}\text { Life expectancy } \\
\text { (years) }\end{array}$} & \multicolumn{2}{c|}{$\begin{array}{c}\text { Per capita HCE } \\
\text { (in 1000 }\end{array}$} & \multicolumn{2}{c|}{ Per capita income } \\
Major Regions & 2006 & 1997 & 2006 & 1997 & 2006 & 1997 & 2005 \\
\hline Northwest & 1.71 & 79.29 & 81.66 & 2.46 & 3.21 & 46.20 & 48.79 \\
West & 1.70 & 79.56 & 81.72 & 1.86 & 2.89 & 41.21 & 41.24 \\
Midlands & 1.02 & 78.89 & 81.11 & 1.91 & 2.77 & 41.39 & 43.14 \\
Center & 0.71 & 79.33 & 81.89 & 1.48 & 2.25 & 40.70 & 44.16 \\
East & 1.06 & 78.75 & 81.54 & 1.59 & 2.33 & 44.56 & 46.48 \\
Zurich & 1.28 & 78.95 & 81.54 & 1.94 & 2.71 & 52.61 & 53.33 \\
\hline Switzerland & 7.48 & 79.12 & 81.57 & 1.94 & 2.78 & 44.11 & 45.71 \\
\hline
\end{tabular}

${ }^{a} 1$ Swiss Franc $=0.85$ US\$.

The Swiss cantons are heterogeneous with respect to the population's life expectancy, health care expenditure and income, as exemplified by the figures for the six major regions presented in Table 1. While life expectancy in the West is not especially high, some of the French and Italian speaking cantons, including Genève, Vaud and Ticino, are among the cantons with the highest life expectancy. ${ }^{4}$ The population in the West incurs the highest level of health care expenditure. In terms of per capita income (again expressed in $2006 \mathrm{SFr}$ ), the West ranges at the lower end of the distribution. Zurich has the highest per capita income but shows average figures in terms of longevity and health care expenditures. The shortest life expectancy is observed in the central and eastern parts of Switzerland, where the average health care expenditure is low. The Center has higher average income than the East. Both the Midlands and the North-West feature average figures in all respects. The increase in real income over the eight years between 1997 and 2005 was very low overall, the average annual growth rate being $0.2 \%$ only. $^{5}$

4 The correlation between per capita health care expenditure and life expectancy is 0.4 on the cantonal level.

5 For 2006, average income values in the cantons are not published yet. 


\section{Medical Technology and the Marginal Cost of Saving a Life}

Let us suppose that at each age the mortality rate is a function of health spending and let the technology be age specific and inhibit decreasing marginal returns:

$$
m_{a}=f_{a}\left(h_{a}\right) \text { with } f_{a}{ }^{\prime}\left(h_{a}\right)<0 \text { and } f_{a}{ }^{\prime \prime}\left(h_{a}\right)>0,
$$

where $m_{a}$ is the mortality rate and $h_{a}$ is the health care expenditure at age $a$. The marginal cost of saving a life at age $a\left(M C L_{a}\right)$ is the necessary increase in health care expenditure to marginally reduce the mortality rate at age $a$, i.e. $M C L_{a}=-d h_{a} / d m_{a}$. From the production function we then have

$$
M C L_{a}=-\frac{1}{f_{a}{ }^{\prime}\left(h_{a}\right)}=\frac{h_{a}}{\theta_{a}\left(h_{a}\right) \cdot f_{a}\left(h_{a}\right)}
$$

where $\theta_{a}\left(h_{a}\right) \equiv-\left(f_{a}{ }^{\prime}\left(h_{a}\right) \cdot h_{a}\right) / f_{a}\left(h_{a}\right)$ is the elasticity of the mortality rate with respect to health care expenditure. According to (2), $M C L_{a}$ is proportional to the health care expenditure, $h_{a}$, and inversely related to the health production elasticity, $\theta_{a}$, and the mortality rate, $m_{a}$. For illustration, if at age 80 the health care expenditure is $12,000 \mathrm{SFr}$, the mortality rate is 10 percent and $\theta_{80}=0.40$, then $M C L_{80}$ is $300,000 \mathrm{SFr}(\approx 255,000$ US\$). By comparison, if at age 35 the average health care expenditure is $2,500 \mathrm{SFr}$, the mortality rate is 0.055 percent and $\theta_{35}=0.45$, this results in an $M C L_{35}$ equal to 10.1 million $\operatorname{SFr}(\approx 8.6$ million US\$).

Equation (2) determines the cost of saving a life from the supply side perspective. The demand side can be inferred from a representative individual, planning health care expenditure over his/her remaining expected lifespan. This leads to the concept of the value of saving a life. ${ }^{6}$ Along the individual's optimal health care spending over the life cycle, the value of saving a life equals its marginal cost at each age. Comparative statics would reveal that an increase in initial wealth increases the value of life. Health is a normal good, so as people get richer they buy more health (see Jones-LeE, 1976).

6 See Rosen (1988) for a seminal presentation of the value of life within in a lifecycle consumption framework. 


\section{Quantitative Analysis}

In the empirical model, we differentiate between two levels, region-specific age classes $(p)$, including 10 age classes $(a)$ in 20 regions $(r)$, and time $(t)$, and assume the following health production function:

$$
m_{p, t}=\gamma_{p, t} \cdot\left(z_{t} \cdot h_{p, t} \cdot w_{p, t}\right)^{-\theta_{p}},
$$

where $\gamma_{p}$ is an efficiency parameter and $\theta_{p}$ is the region- and age-specific elasticity of the inverse of the mortality rate $m_{p}$ with respect to medical inputs $h_{p} . z_{t}$ is the efficiency of a unit of output devoted to health care. Finally, $w_{p, t}$ represents the influence of non-medical inputs such as education and the quality of the environment (air, water pollution, etc.) on the mortality rate.

Taking logs on (3) and adding an error term $e_{p, t}$ yields

$$
\log m_{p, t}=\log \gamma_{p}-\theta_{p} \cdot\left(\log z_{t}+\log h_{p, t}+\log w_{p, t}\right)+e_{p, t} .
$$

We assume a constant exogenous trend in all region, i.e. $\log z_{t}=g_{z} \cdot t$. Moreover, we assume a trend $g_{w, t}$ and a random, non-trended part $\varepsilon_{p, t}$ according to

$$
\log w_{p, t}=\delta \cdot\left(g_{z}+g_{h}\right) \cdot t+\varepsilon_{p, t},
$$

where $g_{z}$ and $g_{h}$ are the respective growth rates of technical progress and of health care expenditure, and $\delta$ is the share of the mortality decline due to non-medical factors. Furthermore, we can exploit the data's panel structure and specify a random-effects model that incorporates region- and age-specific differences. Inserting these expressions into (4) yields:

$$
\log m_{p, t}=\log \gamma_{p}-\theta_{p} \cdot\left(g_{z} \cdot t+\log h_{p, t}+\delta \cdot\left(g_{z}+g_{h}\right) \cdot t\right)+u_{p}+e_{p, t},
$$

where $u_{p}=-\theta_{p} \log \varepsilon_{p, t}$ which in turn leads to:

$$
\begin{gathered}
\log m_{p, t}=\log \gamma_{p}-\theta_{p} \cdot \tilde{h}_{p, t}+u_{p}+e_{p, t}, \\
\text { with } \tilde{h}_{p, t}=g_{z} \cdot t+\delta \cdot\left(g_{z}+g_{h}\right) \cdot t+\log h_{p, t} .
\end{gathered}
$$

We assume that the individual (region- and age-specific) error term $\left(u_{p}\right)$ is constant over time. More important are possible differences between regions and between ages within regions, which we capture with fixed effects of the age 
groups and the regions using dummy variables. The error term $\left(e_{p, t}\right)$ for timedependent shocks features overall zero mean and constant variance. The model's additional assumption then is that $u_{p}$ is uncorrelated with the explanatory variables: $\operatorname{Corr}\left[u_{p} x\right]=0$. By comparison, all within-group observations, i.e. across age groups and accross regions, are correlated with each other: $\operatorname{Corr}\left[e_{p, t}+u_{p}\right.$, $\left.e_{p, s}+u_{p}\right] \neq 0$ for all $t \neq s$. This specification additionally takes into account correlations between age groups across cantons. An alternative would be to use separate random effects for both age groups and regions, which then would be uncorrelated by assumption.

However, due to the time-dependent path of the exogenous and endogenous variables, the explanatory variables might be correlated with $e_{p, t}$. We take into account this possible endogeneity, using an instrumental variable estimator where time serves as an instrument. More specifically, we implement a two-step approach where we first regress the possible endogenous variable on all exogenous variables and the instruments. In the second step, we replace the observed value of the endogenous variable with its estimated value and correct for the standard error in the two-step approach. The model's reduced form can then be written as:

$$
\tilde{h}_{p, t}=\gamma_{p}+\delta_{1} \cdot t+\delta_{2} \cdot t^{2}
$$

In the base case, we set $g_{z}=0.01$ and $\delta=0.5$; i.e. the growth rate of technical progress in medicine is equal to 1 percent per year and non-medical factors have half the impact of health spending on mortality. The real growth rate of health care expenditure $\left(g_{h}\right)$ in the study period was $3.52 \%$ for women and $3.95 \%$ for men, which we accounted for in the regressions.

The limited data set forces us to constrain the number of parameters to be estimated. We choose a two-way approach. First, we focus on the age pattern of the elasticity of the production function, holding the elasticity across regions constant. Then, we free the elasticity across regions while freezing it across age groups. In both regressions, however, we allow for differences in the overall efficiency between ages and regions.

\subsection{Age Differences in the Production Elasticity}

In the first set of estimations we assume a constant $\theta_{a}$ across regions and allow for region- and age-specific differences in the overall efficiency parameters $\gamma_{r}$ and $\gamma_{a}$, respectively: 


$$
\log m_{p, t}=\log \gamma_{r}+\log \gamma_{a}-\theta_{a} \cdot \log \tilde{h}_{p, t}+u_{p}+e_{p, t} .
$$

We estimated (9) for the entire population, and separately for men and women, using 2000 observations each time. Table 2 presents the results for the elasticity of the mortality rate with respect to health spending. The production elasticity is significantly different from zero for all age groups in the overall estimation. More surprising is the fact that the returns to health spending do not decrease in middle and old age. Beyond the age of 50 , the elasticity is more or less constant for both sexes. This result reflects the significant life-year gains that have been produced in recent years, in particular for the old age group.

The overall variance of the error term can be decomposed into two components: $\sigma_{u}$, associated in Table 2 with the individual random effect $\left(u_{p}\right)$, and $\sigma_{e}$ associated with the idiosyncratic error term $\left(e_{p, t}\right)$. Table 2 also gives a value for $\rho$, which is the intra-group correlation and shows the fraction of the overall variance of the error term that can be attributed to the stochastic age and region effect: $\rho=\sigma_{u}^{2} /\left(\sigma_{u}^{2}=\sigma_{e}^{2}\right)$. If $\rho=1$ then the overall variance is entirely determined by the individual (e.g. age- and region-specific) variances. If $\sigma_{u}=0$ then $\rho=0$ and a classical regression model would apply. The Breusch-Pagan-LM-test indicates that $\sigma_{u}$ is significantly different from zero $(p=0.0001)$; hence sufficient heterogeneity between regions and age group exists to apply a random effects model.

The overidentifying restriction test confirms our choice of the instruments. If more instruments are available than necessary for identification, the test indicates whether the additional instruments are valid, i.e. uncorrelated with the error term of the structural equation (see WoOLDRIDGE, 2002, p. 122).

The estimation results reveal significant gender differences. The elasticity of the mortality rate with respect to medical inputs is higher for men than for women. This holds not only for age groups where women incur higher expenditure due to reproductive medicine, but for the entire life cycle. In old age, the men's advantage reflects their larger gain in longevity in the study period. The weighted mean of $\theta$ is 36 percentage points higher for men than for women. If one fixes $\theta$ across the life cycle, a 42 percentage point higher elasticity is realized for men (0.52 as opposed to 0.38 ). This large difference may be explained by two factors: the reduction in mortality was larger for men, while their health care expenditure was smaller than that of women.

With the estimation result for $\theta_{a}$ we can calculate $M C L_{a}$ using the estimated age-specific mortality rate and health care expenditure. Table 3 gives the 2006 values for selected age groups. The average $M C L_{a}$ is 3.4 million SFr $(3.0$ million US\$), which is slightly below the four million to nine million US\$ range given in the literature survey on the value of a statistical life by VISCUSI and ALDI 
(2003). When we do not allow $\theta$ to differ with respect to age, the average value $M C L$ increases to 3.8 million SFr. Decreasing the importance of medical spending for the mortality design by setting $\delta=1$ increases the average value of $M C L$ to 5.1 million $\mathrm{SFr}$, and increasing technical progress in medicine to 2 percent increases it to 4.6 million SFr.

Table 2: The Age-Specific Elasticity of the Mortality Rate with Respect to Health Care Expenditure $\left(\theta_{a}\right)$ and Its Standard Deviation (in Parentheses):

Swiss Population, Women and Men, $g_{z}=0.01, \delta=0.5$

\begin{tabular}{|c|c|c|c|c|c|c|}
\hline \multirow{2}{*}{$\begin{array}{l}\text { Age } \\
0-9\end{array}$} & \multicolumn{2}{|c|}{ All } & \multicolumn{2}{|c|}{ Women } & \multicolumn{2}{|c|}{ Men } \\
\hline & $0.417^{* *}$ & $(0.077)$ & $0.401^{* *}$ & $(0.116)$ & $0.544^{* *}$ & $(0.100)$ \\
\hline $10-19$ & $0.602^{* *}$ & $(0.075)$ & $0.372^{* *}$ & $(0.111)$ & $0.812^{* *}$ & $(0.101)$ \\
\hline $20-29$ & $1.030^{* *}$ & (0.095) & $0.988^{* *}$ & $(0.142)$ & $1.370^{* *}$ & $(0.139)$ \\
\hline $30-39$ & $0.434^{* *}$ & $(0.079)$ & $0.319^{* *}$ & $(0.116)$ & $0.559^{* *}$ & $(0.112)$ \\
\hline $40-49$ & $0.449^{* *}$ & $(0.082)$ & $0.270^{* *}$ & $(0.126)$ & $0.575^{* *}$ & $(0.107)$ \\
\hline $50-59$ & $0.311^{* *}$ & $(0.079)$ & $0.328^{* *}$ & $(0.125)$ & $0.299^{* *}$ & $(0.094)$ \\
\hline $60-69$ & $0.436^{* *}$ & $(0.076)$ & $0.300^{* *}$ & $(0.112)$ & $0.568^{* *}$ & (0.099) \\
\hline $70-79$ & $0.417^{* *}$ & $(0.075)$ & $0.383^{* *}$ & $(0.113)$ & $0.480^{* *}$ & $(0.092)$ \\
\hline 80-89 & $0.373^{* *}$ & $(0.083)$ & $0.386^{* *}$ & $(0.124)$ & $0.408^{* *}$ & $(0.107)$ \\
\hline $90+$ & $0.290^{* *}$ & $(0.093)$ & $0.296^{* *}$ & $(0.137)$ & $0.362^{* *}$ & $(0.141)$ \\
\hline $0-90+{ }^{a}$ & 0.341 & & 0.413 & & 0.586 & \\
\hline $0-90+{ }^{\mathrm{b}}$ & $0.457^{* *}$ & $(0.024)$ & $0.382^{* *}$ & $(0.037)$ & $0.563^{* *}$ & $(0.047)$ \\
\hline$\sigma_{u}$ & $0.103^{* *}$ & & $0.095^{* *}$ & & $0.101^{* *}$ & \\
\hline$\sigma_{e}$ & 0.261 & & 0.311 & & 0.259 & \\
\hline$\rho$ & 0.134 & & 0.084 & & 0.132 & \\
\hline No. of obs. & \multicolumn{2}{|c|}{2000} & \multicolumn{2}{|c|}{2000} & \multicolumn{2}{|c|}{2000} \\
\hline $\mathrm{R}^{2}$ & 0.984 & & 0.918 & & 0.985 & \\
\hline
\end{tabular}

*, $\left({ }^{* *}\right)$ significant at the $90 \%(95 \%)$ confidence level

a weighted average over 20 age classes

b not age-specific $\theta$

The shape of $M C L_{a}$ corresponds to the shape of the value of life over the life cycle. That is well known from the literature (see, for instance, Pratt and ZeckHAUSER, 1996). Beyond a certain age the value of life decreases, the driving force 
being the survival function which discounts future utility. Murphy and TOPEL (2006) calculate that saving a life at age 80 is on average 14 percent the value at age 40, similar to what we find in our estimation. By contrast, Hall and Jones (2007) estimate this value to be 40 percent. Nevertheless, Hall and Jones also find a significantly decreasing $M C L_{a}$ beyond the age of 40 .

Table 3: The Marginal Cost of Saving a Life $(M C L)$ and Its Annual Growth Rate, All, Women And Men, $g_{z}=0.01, \delta=0.5$

\begin{tabular}{lccc|ccc}
\hline & \multicolumn{3}{c|}{ MCL 2006 (in 1,000 SFr) } & \multicolumn{3}{c}{ Average growth rate 1997-2006 (in \%) } \\
Age & All & Women & Men & All & Women & Men \\
\hline $0-9$ & 4,479 & 5,044 & 3,747 & $5.70 \%$ & $5.68 \%$ & $6.24 \%$ \\
$10-19$ & 6,385 & 15,500 & 3,736 & $6.86 \%$ & $5.42 \%$ & $7.85 \%$ \\
$20-29$ & 2,775 & 7,563 & 1,222 & $7.00 \%$ & $6.77 \%$ & $7.62 \%$ \\
$30-39$ & 5,967 & 5,600 & 2,796 & $5.61 \%$ & $4.99 \%$ & $5.69 \%$ \\
$40-49$ & 2,936 & 7,298 & 1,751 & $5.63 \%$ & $4.37 \%$ & $6.46 \%$ \\
$50-59$ & 2,377 & 3,410 & 1,849 & $5.25 \%$ & $4.88 \%$ & $5.69 \%$ \\
$60-69$ & 1,087 & 2,239 & 667 & $6.62 \%$ & $5.74 \%$ & $7.32 \%$ \\
$70-79$ & 626 & 894 & 428 & $6.67 \%$ & $6.29 \%$ & $7.22 \%$ \\
$80-89$ & 328 & 374 & 247 & $5.44 \%$ & $5.41 \%$ & $5.80 \%$ \\
$90+$ & 246 & 266 & 182 & $3.64 \%$ & $3.80 \%$ & $3.24 \%$ \\
\hline $0-90+^{\mathrm{a}}$ & 3,414 & 7,363 & 2,095 & $5.68 \%$ & $5.05 \%$ & $6.16 \%$ \\
$0-90+{ }^{\mathrm{b}}$ & 3,758 & 7,728 & 2,282 & $5.15 \%$ & $4.49 \%$ & $5.64 \%$ \\
\hline
\end{tabular}

a weighted average over 20 age classes

b not age-specific $\theta$

For the calculation of the average gender $M C L$ ratio, using (2), we need to standardize the different age structures of the female and male populations. For simplicity, we use the age structure of the 2006 Swiss population for standardization. The results are presented in the last two rows of Table 4 for the estimations with and without age-specific $\theta_{a}$. The average gender $M C L$ ratio is around 3.5. The strongest influence comes from the higher mortality rate of men, followed by the higher elasticity of health production for men and the higher health care expenditure of women.

The $M C L$ gender ratio varies over the life cycle. It is highest between age 20 and age 50 and lowest at the two ends of the life cycle. The higher male mortality 
rate dominates the gender ratio of MCL around 20. Around age 30 the high health care expenditure of women in connection with motherhood and the corresponding low health production elasticity have a strong effect on the gender ratio. At age 60, it is the higher production elasticity of men which increases the gender difference of $M C L$. The latter points to the reduced male mortality achieved through technical progress in the treatment of cardiovascular diseases.

Table 4: A Decomposition of the MCL Gender Gap, 2006

\begin{tabular}{lcccc}
\hline Age & $M C L_{a}(W)$ & $\frac{h_{a}(W)}{h_{a}(M)}$ & $\frac{\theta_{a}(W)}{\theta_{a}(M)}$ & $\frac{m_{a}(W)}{m_{a}(M)}$ \\
\hline $0-9$ & 1.35 & 0.84 & 1.36 & 1.26 \\
$10-19$ & 4.15 & 1.21 & 2.18 & 2.01 \\
$20-29$ & 6.19 & 1.96 & 1.39 & 2.76 \\
$30-39$ & 5.58 & 1.80 & 1.75 & 1.95 \\
$40-49$ & 4.17 & 1.35 & 2.13 & 1.70 \\
$50-59$ & 1.84 & 1.18 & 0.91 & 1.80 \\
$60-69$ & 3.36 & 0.99 & 1.89 & 1.98 \\
$70-79$ & 2.09 & 0.97 & 1.25 & 1.83 \\
$80-89$ & 1.51 & 1.13 & 1.06 & 1.41 \\
$90+$ & 1.46 & 1.25 & 1.22 & 1.18 \\
\hline $0-90+{ }^{a}$ & 3.52 & 1.38 & 1.42 & 1.46 \\
\hline
\end{tabular}

a weighted average over 20 age classes using the Swiss population

\subsection{Regional Differences in the Production Elasticity}

In the second set of regressions we focus on differences in the production elasticity on the regional level, while allowing age- and region-specific overall efficiency according to:

$$
\log m_{p, t}=\log \gamma_{a}+\log \gamma_{r}-\theta_{r} \cdot \log \tilde{h}_{p, t}+u_{p}+e_{p, t} .
$$

The GMM estimation results for regional mortality rates for women and men are presented in Table 5. Again we used time and time squared as instruments; the overidentification test validates this choice. We observe little difference in $\gamma$, 
between the regions when compared to the benchmark Aargau. Regarding the elasticity of the mortality rate with respect to health inputs, the estimation results indicate some differences between the cantons. For three cantons, the elasticity is not significantly different from zero in the estimation for women. The average values of the elasticity for men and women are about the same as in the Swiss estimation; the gender difference in the elasticity is roughly 12 percentage points.

Table 5: Regional Differences in the Medical Technology

\begin{tabular}{|c|c|c|c|c|c|}
\hline \multirow[b]{2}{*}{ Major Regions } & \multirow[b]{2}{*}{ Cantons } & \multicolumn{2}{|c|}{ Women } & \multicolumn{2}{|c|}{ Men } \\
\hline & & $\log \gamma_{r}$ & $\theta_{r}$ & $\log \gamma_{r}$ & $\theta_{r}$ \\
\hline \multirow[t]{3}{*}{ North-West } & Aargau & $5.66^{* *}$ & $0.328^{* *}$ & $5.26^{* *}$ & $0.360^{* *}$ \\
\hline & Basel-Land & -1.39 & $0.501^{* *}$ & -1.88 & $0.607^{* *}$ \\
\hline & Basel-Stadt & -1.91 & $0.526^{* *}$ & $-4.88^{* *}$ & $0.934^{* *}$ \\
\hline \multirow[t]{4}{*}{ West } & Genève & -2.88 & $0.676^{* *}$ & -3.05 & $0.729^{* *}$ \\
\hline & Ticino & -2.52 & $0.643^{* *}$ & -1.13 & $0.488^{* *}$ \\
\hline & Valais & -0.14 & $0.333^{* *}$ & -1.16 & $0.491^{* *}$ \\
\hline & Vaud & -1.44 & $0.496^{*}$ & 0.03 & $0.331^{* *}$ \\
\hline \multirow[t]{4}{*}{ Midlands } & Bern, Jura & 0.15 & $0.304^{* *}$ & -0.60 & $0.429^{* *}$ \\
\hline & Fribourg & -0.79 & $0.413^{* *}$ & -0.97 & $0.457^{* *}$ \\
\hline & Neuchâtel & $-3.67^{*}$ & $0.766^{* *}$ & -0.68 & $0.436^{* *}$ \\
\hline & Solothurn & -0.31 & $0.361^{* *}$ & -0.43 & $0.411^{* *}$ \\
\hline \multirow[t]{3}{*}{ Central } & Luzern & -1.39 & $0.286^{*}$ & -0.32 & $0.407^{* *}$ \\
\hline & Nid- and Obwalden, Uri & -1.91 & 0.211 & $-3.96^{* *}$ & $0.898^{* *}$ \\
\hline & Schwyz, Zug & 0.40 & $0.561^{* *}$ & -0.96 & $0.485^{* *}$ \\
\hline \multirow[t]{5}{*}{ East } & Appenzell IR and AR & 0.99 & 0.023 & -1.40 & $0.544^{* *}$ \\
\hline & Glarus, Graubünden & -1.83 & $0.284^{*}$ & -2.02 & $0.610^{* *}$ \\
\hline & Schaffhausen & 2.44 & 0.060 & -0.61 & $0.437^{* *}$ \\
\hline & St. Gallen & 0.40 & $0.523^{* *}$ & -1.31 & $0.519^{* *}$ \\
\hline & Thurgau & 2.04 & $0.241^{* *}$ & -1.53 & $0.549^{* *}$ \\
\hline \multicolumn{2}{|l|}{ Zürich } & -1.57 & $0.303^{*}$ & -1.33 & $0.512^{* *}$ \\
\hline \multicolumn{2}{|l|}{ Mean $^{a}$} & & 0.394 & & 0.502 \\
\hline \multicolumn{2}{|l|}{ Mean $^{b}$} & & $0.382^{* *}$ & & $0.518^{* *}$ \\
\hline \multicolumn{2}{|c|}{ Number of observations } & \multicolumn{2}{|c|}{2000} & \multicolumn{2}{|c|}{2000} \\
\hline \multicolumn{2}{|c|}{$\sigma_{u}$} & \multicolumn{2}{|c|}{$0.143^{* *}$} & \multicolumn{2}{|c|}{$0.163^{* *}$} \\
\hline \multicolumn{2}{|l|}{$\begin{array}{l}\sigma_{e} \\
\rho\end{array}$} & \multicolumn{2}{|c|}{0.308} & \multicolumn{2}{|c|}{0.260} \\
\hline \multirow{2}{*}{\multicolumn{2}{|c|}{$\begin{array}{l}\rho \\
\mathrm{R}^{2}\end{array}$}} & \multicolumn{2}{|c|}{0.178} & \multicolumn{2}{|c|}{0.132} \\
\hline & $\mathrm{R}^{2}$ & \multicolumn{2}{|c|}{0.976} & \multicolumn{2}{|c|}{0.979} \\
\hline
\end{tabular}

a weighted average over 20 age classes

b not age-specific $\theta$ 
Finally, there is a substantial variation in $M C L$ between the regions (see Table 6). We find the lowest (significant) MCL for women in Ticino (4.7 million SFr) and for men in the centre of Switzerland (Nid- and Obwalden and Uri) (1.1 million SFr) and the highest for women in Glarus and Graubünden (10.9 million SFr) and for men in Aargau (3.7 million SFr). The gender ratio of $M C L$ varies between 1.2 and 6.5 , the weighted mean being 4 . Compared to the estimation on the federal level, the higher gender ratio is explained by a larger difference in the mortality rates $(m(M) / m(W)=1.86)$ and a lower difference in the production elasticity $(\theta(M) / \theta(W)=1.29)$ on the regional level.

Table 6: Regional Differences in the Marginal Cost of Saving a Life (MCL)

\begin{tabular}{|c|c|c|c|c|}
\hline Major Regions & Cantons & $\begin{array}{l}\text { Women } \\
\text { MCL } 2006 \\
\text { (in } 1000 \text { SFr) }\end{array}$ & $\begin{array}{c}\text { Men } \\
\text { MCL } 2006 \\
\text { (in } 1,000 \mathrm{SFr} \text { ) }\end{array}$ & Gender ratio \\
\hline North-West & $\begin{array}{l}\text { Aargau } \\
\text { Basel-Land } \\
\text { Basel-Stadt }\end{array}$ & $\begin{array}{l}9,323 \\
6,811 \\
4,944\end{array}$ & $\begin{array}{l}3,653 \\
2,535 \\
1,159\end{array}$ & $\begin{array}{l}2.55 \\
2.69 \\
4.27\end{array}$ \\
\hline West & $\begin{array}{l}\text { Genève } \\
\text { Ticino } \\
\text { Valais } \\
\text { Vaud }\end{array}$ & $\begin{array}{l}5,254 \\
4,661 \\
9,881 \\
5,452\end{array}$ & $\begin{array}{l}1,736 \\
2,605 \\
2,673 \\
3,432\end{array}$ & $\begin{array}{l}3.03 \\
1.79 \\
3.70 \\
1.59\end{array}$ \\
\hline Midlands & $\begin{array}{l}\text { Berne, Jura } \\
\text { Fribourg } \\
\text { Neuchâtel } \\
\text { Solothurn }\end{array}$ & $\begin{array}{l}8,622 \\
7,545 \\
2,586 \\
7,576\end{array}$ & $\begin{array}{l}2,461 \\
2,449 \\
2,237 \\
3,104\end{array}$ & $\begin{array}{l}3.50 \\
3.08 \\
1.16 \\
2.44\end{array}$ \\
\hline Central & $\begin{array}{l}\text { Luzern } \\
\text { Nid- and Obwalden, Uri } \\
\text { Schwyz, Zug }\end{array}$ & $\begin{array}{l}9,616 \\
- \\
5,047\end{array}$ & $\begin{array}{l}2,723 \\
1,065 \\
2,325\end{array}$ & $\begin{array}{c}3.53 \\
- \\
2.17\end{array}$ \\
\hline East & $\begin{array}{l}\text { Appenzell IR and AR } \\
\text { Glarus, Graubünden } \\
\text { Schaffhausen } \\
\text { St. Gallen } \\
\text { Thurgau }\end{array}$ & $\begin{array}{c}- \\
10,900 \\
- \\
5,436 \\
13,100\end{array}$ & $\begin{array}{l}1,842 \\
1,717 \\
2,694 \\
2,361 \\
2,030\end{array}$ & $\begin{array}{c}- \\
6.35 \\
- \\
2.30 \\
6.45\end{array}$ \\
\hline Zürich & & 9,981 & 2,502 & 3.99 \\
\hline
\end{tabular}

Regressing $M C L$ on income per capita in the regions and using regional fixed effects leads to a significant coefficient. The income elasticity of $M C L$ amounts 
to 0.93 . This value is substantially lower than the result of Costa and KAHN (2004), who report an income elasticity of 1.6 for the value of a statistical life in the time period 1940-1980 for the USA. The difference may be due to the standard catalogue of mandatory health care services in Switzerland.

Recently, the gender gap in longevity has gained some interest in the literature. LeUng et al. (2006) find evidence for the USA that the closing wage gap in the post-1970 period contributed to the declining gender longevity gap. FELDER (2006b) shows that if household preferences are characterized by constant absolute risk aversion or low relative risk aversion, an increase in wealth will, ceteris paribus, reduce the gender longevity gap. The average gender longevity gap in Switzerland was shortened from 5.79 years in 1997 to 4.89 years in 2006 . Yet, the variation between cantons is large. In 2006, the gender longevity gap was the largest in the canton of Valais (6.06 years) and smallest in the Canton of Schaffhausen (3.05 years). In the cross-sectional estimation as well as in the longitudinal panel structure, we find a significant negative income effect on the longevity gender gap.

\section{Conclusion}

Unlike other European countries such as Great Britain, France and Germany, Switzerland has always followed a decentralized policy in health care. The sickness funds' premiums are allowed to differ between regions, and subsidies to the stationary health care sector as well as health premium subsidies to low-income individuals are governed by the local authorities, which are endowed with their own tax revenues. The pertinent federalism in health care has led to different regional levels of health care provision and corresponding expenditures (see Crivelli et al., 2006). For instance, the West of Switzerland spends almost twice as much on health care as the East. Interestingly enough, larger spending comes with higher longevity: a correlation coefficient of 0.4 indicates a positive relationship between health spending and longevity.

Switzerland shares a gender longevity gap in favor of women with other countries. Currently women's life expectancy is 5 years higher than men's. At the same time, women also incur higher health care expenditure not only in their twenties and thirties, when a substantial part is spent on reproductive medicine, but also in old age. This again poses the question whether higher spending on health causes higher longevity.

We estimated age-specific production functions relating the mortality rate to health care expenditures. Using the estimated coefficients, we then calculated 
the marginal cost of saving a life $(M C L)$, i.e. the additional expenditure required to save a life. Regarding the regional results, we found no significant differences with respect to the overall efficiency of the production function between the regions. It thus appears that medical technology is more or less the same across all Swiss regions. Substantial differences in $M C L$ arise mainly due to large differences in per capita health care expenditure between the regions. Regressing $M C L$ on the regional per capita income lends support to the claim that the value of life is a normal good. The estimated income elasticity is 0.93 , however, thus smaller than the results reported in other studies.

With regard to the age characteristics of medical technology, the elasticity of the mortality rate with respect to health spending is higher at young ages. Beyond the age of 40 , the elasticity is more or less constant. In particular, the elasticity of medical inputs does not decrease in old age, reflecting substantial reductions in mortality in recent years. The shape of $M C L$ across the life cycle is found to be similar to that of the value of life well known from the pertinent literature. $M C L$ has a decreasing shape beyond the age of 40 , driven by both increasing health care expenditure and increasing mortality rates.

The quantitative analysis reveals significant differences in the health production parameters between men and women. The elasticity of the mortality rate with respect to health spending is significantly higher for men. This result even holds in old age. It can be explained by the recent larger gains in longevity for men. Lower elasticity of health production, lower mortality rates and higher health care expenditure result in a substantially higher $M C L$ for women. The estimated $M C L$ gender factor is around 3.5 in Switzerland.

Given the gender gap in longevity, Richard Posner argued for the transfer of government spending on health care from old women to old men because shortening the gender gap "would give elderly women a greater prospect of male companionship, something many of them greatly value" (PosNer, 1995, p. 277). If $M C L$ for women is in fact larger than that for men, as this study finds, Posner has an even stronger case.

\section{References}

Becker, Gary S., Thomas J. Philipson, and Rodrigo R. Soares (2005), “The Quantity and Quality of Life and the Evolution of World Health Inequality", American Economic Review, 95, pp. 277-291.

Costa, Dora L., and Matthew E. Kahn (2004), "Changes in the Value of Life, 1940-1980”, Journal of Risk and Uncertainty, 29(2), pp. 159-180. 
Crivelli, Luca, Massimo Filippini, and Ilaria Mosca (2006), "Federalism and Regional Health Care Expenditures: An Empirical Analysis for the Swiss Cantons", Health Economics, 15, pp. 535-541.

Cutler, David M., and Marc McClellan (2001), "Is Technological Change in Medicine Worth It?", Health Affairs, 20(5), pp. 11-29.

Cutler, David M., Angus S. Deaton, and Adriana Lleras-Muney (2006), "The Determinants of Mortality", Journal of Economic Perspectives, XX, pp. 97-120.

Felder, Stefan (2006a), „Lebenserwartung, Medizinischer Fortschritt und Gesundheitsausgaben: Theorie und Empirie", Perspektiven der Wirtschaftspolitik, 7 (Special issue), pp. 49-73, 2006.

Felder, Stefan (2006b), “The Longevity Gender Gap: Explaining the Difference between Singles and Couples", Journal of Population Economics, 19(3), pp. 543-557.

Hall, Robert E., and Charles I. Jones (2007), "The Value and the Rise in Health Spending", The Quarterly Journal of Economics, 122(1), pp.39-72.

Jones-Lee, Michael W. (1976), The Value of Life: An Economic Analysis, Chicago: University of Chicago Press.

Leung, Michael C. M., Jie Zhang, and Junsen Zhang (2004), "An Economic Analysis of Life Expectancy by Gender with Application to the United States", Journal of Health Economics 23(4), pp. 737-759.

Murphy, Kevin M., and Robert H. Topel (2006), "The Value of Health and Longevity”, Journal of Political Economy 114(5), pp. 871-904.

OECD (2008), OECD Health Data, OECD, Paris.

Posner, Richard (1995), Aging and Old Age, University Press, Chicago.

Pratt, John W., and Richard J. Zeckhauser (1996), "Willingness to Pay and the Distribution of Risk and Wealth", Journal of Political Economy, 104, pp. 747-763.

Rosen, Sherwin (1988), "The Value of Changes in Life Expectancy”, Journal of Risk and Uncertainty, 1, pp. 285-304.

Schleiniger, Reto, Tilman Slembeck, and Jonas Blöchliger (2006), "Kantonale Preis- und Mengenindizes der OKP-Gesundheitsleistungen - Methode und Resultate", mimeo, Zentrum für Wirtschaftspolitik, Zürcher Hochschule Winterthur.

Viscusi, W. Kip., and Joseph E. Aldy (2003), "The Value of Saving a Life: A Critical Review of Market Estimates Throughout the World", Journal of Risk and Uncertainty, 27, pp. 5-76.

Wooldridge, Jeffrey M. (2002), Econometric Analysis of Cross Section and Panel Data, Cambridge (Massachusetts) et al. 


\section{SUMMARY}

This paper estimates the marginal cost of saving a life using age- and genderspecific health care expenditures and mortality rates of the 26 Swiss cantons for the period 1997 to 2006. It shows almost triple the marginal cost of saving a life for women as compared to men, reflecting a lower marginal elasticity of medical inputs, a lower mortality rate and higher spending on health care for women. Medical technology does not differ across cantons while the marginal cost of saving a life does. Wealthy cantons spend more on saving a life at the margin and show a smaller gender gap in longevity. 